\title{
Blended Learning Potencializando a Aprendizagem da Estatística no Ensino Superior
}

\section{Blendled Learning: Enhancing the Statistics Learning in Higher Education}

\author{
Gabriela Machado Moura \\ Universidade Federal do Rio Grande \\ Suzi Samá \\ Universidade Federal do Rio Grande
}

\begin{abstract}
Resumo: A velocidade e profusão de dados gerados pelas novas tecnologias exige dos profissionais das diversas áreas do conhecimento competência para organizar, analisar e interpretar dados. Além disso, a sala de aula tradicional de estatística não atende aos anseios e comportamentos das novas gerações que nasceram imersas nas tecnologias digitais. Neste sentido, o presente artigo tem por objetivo apresentar e avaliar a proposta pedagógica da Sala de Aprendizagem da Estatística planejada a partir da modalidade Blended Learning. Esta forma híbrida de ensino envolve a utilização de vídeos, jogos, simulações, coleta de dados, atividades em grupo e individualizadas, de forma a potencializar a aprendizagem dos conceitos de estatística. A partir da análise da opinião dos estudantes de graduação, realizada por meio de métodos qualitativos e quantitativos, constatamos que estes valorizaram a diversidade de suportes e estratégias pedagógicas utilizados ao longo da disciplina de Estatística.
\end{abstract}

Palavras-chave: Ensino de Estatística. Tecnologias digitais. Blended Learning. Teoria da Biologia do Conhecer. Ensino Superior.

\begin{abstract}
The velocity and the abundance of data generated by the new technologies requires professionals from different areas of expertise to organize, analyze, and interpret data. In addition, the traditional statistical classroom does not meet the yearnings and behaviors of the new generations who were born immersed in digital technologies. Following, the present article aims to present and to evaluate the pedagogical proposal of the Statistics Learning Room planned from the modality Blended Learning. This hybrid way of teaching involves the use of videos, games, simulations, data collection, group and individualized activities, in order to enhance the learning of the concepts of statistics. From the analysis of undergraduation students' opinion, carried out by means of qualitative and quantitative methods, we verified that they value the diversity of pedagogical supports and strategies used throughout the Statistics course.
\end{abstract}

Keywords: Teaching Statistics. Digital Technologies. Blended Learning. Knowing Biology Theory. Higher Education. 


\section{Introdução}

A Estatística contribui cientifica e tecnologicamente com a sociedade na medida em que os cidadãos passam a responder adequadamente às demandas sociais que envolvem o tratamento da informação e a produção de conhecimento. Além disso, o acesso aos recursos tecnológicos digitais potencializa e amplia a utilização das técnicas estatística de redução e análise de dados a todas as áreas do conhecimento

Assim, a Internet, ao criar novas possibilidades para o acesso à informação, modifica o trabalho humano e traz novas formas de produzir, armazenar, processar, recuperar e transmitir informações, gerando novos hábitos e formas de pensar. Segundo Moraes (2007), vivemos a Era das Relações, a qual requer que o conhecimento seja visto como um processo em continuidade, no qual o produto resultante nunca está completamente pronto e acabado.

Os jovens desta geração, nascidos imersos nas mídias digitais interativas, têm comportamentos e anseios diferentes das gerações anteriores, exigem maior interação e desafios (OLIVEIRA, 2010). Segundo Belloni (2006), o mundo digital demanda um trabalhador multicompetente, multiqualificado, capaz de trabalhar coletivamente, sempre pronto a aprender, em suma um trabalhador mais informado e autônomo.

Desta forma, "uma nova cultura surge por meio de uma dinâmica sistêmica, na qual a rede de conversações em que a comunidade em processo de mudança cultural vive, modifica-se, guiada e demarcada precisamente pela nova configuração do emocionar." (MATURANA e VERDEN-ZOLLER, 2009, p14). Essa mudança cultural exige o repensar dos espaços e tempos educativos, profissionais e sociais, a fim de adequá-los as novas demandas, porém, com um sentido amplo e coletivo em direção à melhoria social e conquista da cidadania

Para Samá, Araújo e Laurino (2011), o conhecimento não pode ser alcançado no isolamento do indivíduo, uma vez que o conhecer ocorre na interação dos indivíduos com o ambiente em que vivem. Neste sentido, considerar o contexto de vida de cada comunidade é importante no processo educacional. Ainda segundo as autoras, compartilhar vivências é necessário na (re)construção de conceitos, para compreender o próprio conhecimento e o mundo que fazemos emergir a partir de nosso atuar.

Neste sentido, o Grupo de Pesquisa em Educação Estatística de nossa instituição tem buscado planejar o espaço da sala de aula de Estatística de forma a atender as mudanças culturais promovidas pelos avanços das tecnologias digitais. Para tal, foi organizada uma sala de aula para o ensino da Estatística a fim de integrar elementos de um ambiente de aprendizado presencial com a flexibilidade e os recursos digitais utilizados na Educação a Distância.

Esta forma híbrida de ensino, denominada Blended Learning, é uma tentativa de oferecer as vantagens da educação a distância combinadas com todos os benefícios da sala de aula tradicional (MARSH, 2003; PASCUAL, 2003) de forma a responder aos anseios das novas gerações. O presente artigo tem por objetivo apresentar este ambiente híbrido, bem como avaliar a opinião dos estudantes sobre ele.

Nessa seção apresentamos uma breve introdução da temática do artigo, na próxima seção tecemos algumas reflexões sobre o repensar do espaço da sala de aula de Estatística fundamentadas na Teoria da Biologia do Conhecer de Maturana e Varela (2005), bem como a contribuição do Blended Learning neste repensar. Na sequência apresentamos as atividades e recursos da SalAEst, a metodologia e a análise da avaliação dos estudantes. Por fim, apontamos algumas considerações.

\section{Repensando o Espaço Educacional}

De acordo com a Teoria da Biologia do Conhecer, proposta por Maturana e Varela (2005), o viver não se separa do conhecer, o que nos leva a refletir sobre os métodos pedagógicos tradicionais que, em geral, são processos mecânicos, estranhos ao viver e, muitas vezes, indesejáveis para a ontogenia dos sujeitos cognitivos. 
Para Maturana e Varela (2005), o aprender pode ser entendido como uma adaptação, pois o conhecimento dá-se pela interação entre a pessoa e o meio (que pode ser o professor, outros estudantes ou até mesmo as tecnologias digitais). Partindo deste pressuposto, entendemos o papel do professor como um desencadeador de perturbações que gerem adaptações, promovendo, assim, mudanças estruturais no estudante, de forma que este desenvolva outras aprendizagens.

Se assim compreendemos o conhecer e o aprender, não podemos concordar com práticas de ensino com ênfase na exposição dialogada centrada no docente, com baixo índice de participação dos estudantes. Isto porque tais práticas inviabilizam, muitas vezes, que estes expressem o que vivenciam, além de serem focadas, em sua maioria, na comunicação de informações e conceitos pré-definidos.

Se os educadores assumirem a interação como um pressuposto para o aprender, segundo Pellanda (2009), terão que repensar suas práticas e estratégias pedagógicas. Este repensar deve ocorrer no intuito de que se possibilite a participação efetiva de cada estudante na construção de seu conhecimento, bem como no desenvolvimento de competências que realmente importem para os sujeitos aprendentes no fluxo do viver.

No entanto, o que temos observado no ensino de Estatística é que muitas vezes o estudante consegue resolver um exercício envolvendo média, desvio-padrão e correlação, mas não sabe interpretar estas medidas estatísticas ou até mesmo analisar um simples gráfico. Tal situação evidencia a desconexão entre o conhecimento ensinado e testado nas instituições de ensino e o que é exigido na vida social e profissional.

Segundo Garfield e Gal (1999), à medida que os estudantes adquirem maior conhecimento estatístico podem também ser capazes de questionar a validade das interpretações de dados e das decisões tomadas e generalizações realizadas com base em pesquisas científicas. Isto possibilita que estes desenvolvam seu potencial de forma mais crítica e autônoma.

Para Gal (2002), fazer estatísticas não é equivalente a compreender estatísticas. Ser capaz de calcular, por exemplo, um desvio padrão, não demonstra a habilidade do estudante para entender o que o desvio padrão é, o que ele mede, ou como ele é usado, por isso cálculos não devem ser o centro das atenções em uma sala de aula. "Na análise de dados, o contexto fornece o significado" (p.803). Para Batanero e Borovcnik (2016) qualquer investigação estatística sempre começa com perguntas que surgem de um contexto. Os autores, ainda destacam a importância dos estudantes estarem familiarizados com o contexto da pesquisa, pois assim os métodos estatísticos utilizados para responder essas perguntas farão mais sentido para eles.

Conscientes desta realidade, o Grupo de Pesquisa em Educação Estatística de nossa instituição busca promover um ambiente educacional instigante e participativo por meio do Blended Learning, o qual parte do pressuposto de que não há uma única forma de aprender e, por consequência, não há uma única forma de ensinar. Fundamentalmente, esta modalidade congrega atividades presenciais e atividades a distância. Os princípios do Blended Learning são: criar um ambiente de motivação para engajar os alunos nas atividades; possibilitar a reflexão como forma de construção dos conceitos; estimular a cooperação entre os participantes; desenvolver a autonomia na busca da informação e a capacidade de investigação; promover a integração de momentos presenciais e virtuais, banco de testes para avaliação formativa e rotação de estações com diferentes propostas de ensino.

No Blended Learning o trabalho colaborativo pode estar aliado ao uso das tecnologias digitais e propiciar momentos de aprendizagem e troca, que ultrapassam as barreiras da sala de aula. Para Bacich e Moran (2015) aprender com os pares torna-se ainda mais significativo quando há um objetivo comum a ser alcançado pelo grupo.

Twigg (2003) apresenta os resultados encontrados em dez cursos de diferentes instituições em que foram introduzidos tecnologias no âmbito de um modelo de "Blended Learning". Todos os projetos encontraram aumentos significativos na relação ensino e aprendizagem, tornando o processo mais ativo e centrado no aluno. O objetivo principal é mover o estudante de uma atitude 
passiva para um papel mais ativo na construção de sua aprendizagem, o que caracteriza esta modalidade de ensino dentro de concepções epistemológicas construtivistas/interacionistas.

Com base nesses pressupostos do Blended Learning e da Biologia do Conhecer, o Grupo de Pesquisa conta com uma sala de aula especial, Sala de Aprendizagem de Estatística (SalAEst), Figura 1, e com o Laboratório de Estudos Cognitivos e Tecnologias na Educação Estatística (LabEst).

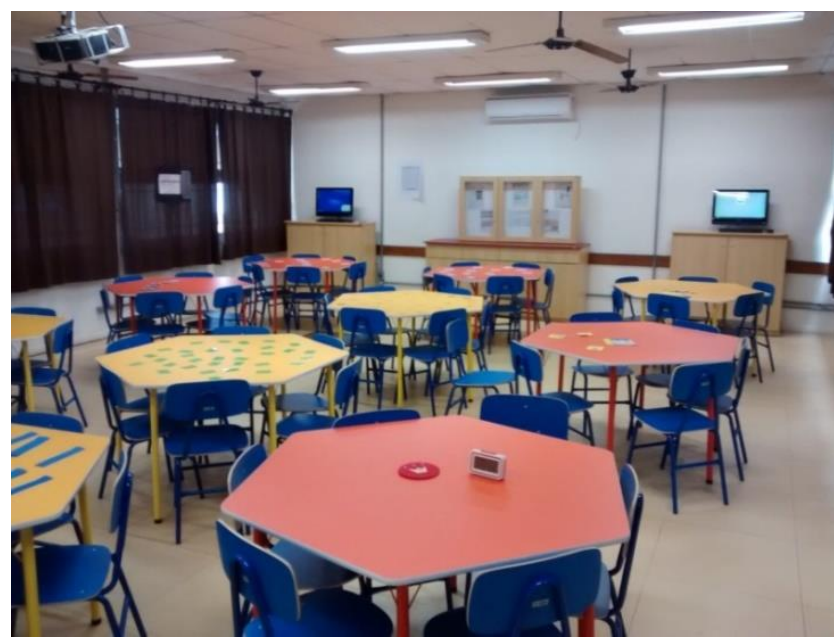

Figura 1. Sala de Aprendizagem de Estatística (SalAEst)

Fonte: Arquivo da SalAESt

Estes são equipados com computadores, lousa digital, tablets e multimídia bem como dez mesas hexagonais que potencializam a interação e o debate entre os estudantes. Além disso, no LabEst e na SalAEst, atuam orientandos de pós-graduação e bolsistas vinculados a projetos de ensino, extensão e pesquisa, envolvendo a promoção da ciência e tecnologia na resolução de problemas das diversas áreas de atuação da equipe proponente.

O planejamento do LabEst e da SalAEst visa promover o ensino e a aprendizagem da estatística em um ambiente educacional flexível que possibilite a ação e a interação dos estudantes por meio de projetos de pesquisa em grupo, simulações, ambiente virtual de aprendizagem, material concreto e recursos audiovisuais. Com isso, pretende-se ampliar o conceito de aula, de interação e pesquisa para além da presença física em um mesmo espaço e ao mesmo tempo.

Segundo Moran (2013), o ensino híbrido está emergindo como uma inovação sustentada em relação à sala de aula tradicional, em que os espaços educacionais estão sendo repensados para espaços mais abertos, onde lazer e estudo estejam mais integrados. Segundo o autor, precisamos "dar menos aulas". Para tanto, é importante um planejamento cuidadoso do espaço de aprendizagem: disponibilizar na internet o conteúdo fundamental, elaborar um plano de ensino que oriente os estudantes quanto ao seu percurso pedagógico, promover atividades mais instigantes para os estudantes com a orientação do professor, associar diferentes materiais pedagógicos, como vídeos e textos nos ambientes virtuais, com atividades de aprofundamento nos espaços físicos.

\section{Atividades e recursos da SalAEst}

Nesta seção, apresentamos a disciplina, foco da pesquisa desse artigo, bem como alguns dos suportes pedagógicos e teórico-metodológicos que sustentam as atividades realizadas na SalAEst, os quais são usados com a finalidade de promover a aprendizagem dos conceitos da Probabilidade e Estatística das disciplinas ministradas na sala. 
A disciplina previa em sua ementa conteúdos de Estatística Inferencial (amostragem, distribuições amostrais, intervalos de confiança, testes de hipóteses, análise de regressão e correlação), ministrados durante o semestre em dois encontros semanais de duas horas cada, o que totalizou quatro créditos. Essa foi organizada no ambiente virtual Moodle, o qual é mantido atualizado e com as orientações sobre os conteúdos e atividades da disciplina. A seguir, apresentamos as atividades e os recursos pedagógicos propostos a partir da Teoria da Biologia do Conhecer e do Blended Learning.

\subsection{Projetos de Aprendizagem (PA) ${ }^{1}$}

Consistem na realização de uma pesquisa que parte de um tema do interesse dos estudantes. Um PA compreende as seguintes etapas, todas permeadas pelo tema escolhido: planejamento, pesquisa propriamente dita, método de amostragem, coleta, apresentação e organização de dados. As atividades são realizadas em grupo, com o objetivo de proporcionar a discussão de ideias e promover a aprendizagem de forma dinâmica, através da cooperação entre os estudantes. Ao final, estes elaboram um relatório com os resultados da pesquisa e apresentam para os demais colegas.

Segundo Fagundes, Sato e Maçada-Laurino (1999), o ensino pela pesquisa possibilita que os estudantes ampliem sua rede de significações. O raciocínio passa a ser reestruturado, enquanto elabora sínteses de respostas descritivas e explicativas para o tema investigado. Vários pesquisadores da área da Educação Estatística, como Mendonça e Lopes (2011); Porciúncula e Samá (2014); Velasque, Barbosa e Silva (2016), defendem o ensino de Estatística por meio de projetos como uma forma de desenvolver o raciocínio e o Letramento Estatístico ${ }^{2}$.

\subsection{Videoaulas}

Estas possibilitam aos estudantes retomarem os conceitos trabalhados em aula e ampliam o espaço-tempo da sala para além do físico. De acordo com Mattar (2009), os vídeos têm sido cada vez mais utilizados como recurso pedagógico, atendendo aos múltiplos estilos de aprendizagem. Para o autor, "muitos alunos aprendem melhor quando submetidos a estímulos visuais e sonoros, em comparação com uma educação tradicional" (p.3).

O link para cada uma das videoaulas (Figura 2), disponível no Youtube, é inserido nos respectivos tópicos do conteúdo correspondente, na Plataforma Moodle, Ambiente Virtual de Aprendizagem das disciplinas de Estatística.

\subsection{Plataforma Moodle}

Esta ferramenta de ensino, assim como as videoaulas, também amplia o espaço-tempo da sala de aula. O Moodle permite a criação e administração de grupos de trabalho, comunidades de aprendizagem, bem como a disponibilização e organização de material didático pedagógico. Segundo Ribeiro, Mendonça e Mendonça (2007) o Moodle:

"Oferece um conjunto de ferramentas de comunicação e discussão (fórum, bate-papo, diálogos), assim como de avaliação e construção coletiva (Teste, trabalhos, workshops, wikis, glossários), e de disponibilização de materiais (lições, livros) ou de pesquisa (pesquisa de opinião e questionários) (p.9)".

A diversidade de possibilidades de atividades e ferramentas são um dos destaques do Moodle. Com a finalidade de explorar as referidas funcionalidades do Moodle, disponibilizamos os

\footnotetext{
1 Maiores detalhes a respeito dos PA no ensino de Estatística podem ser obtidos em Porciúncula e Samá (2014).

20 letramento estatístico é definido por Gal (2002) como a habilidade do indivíduo em interpretar e avaliar criticamente as informações estatísticas, bem como comunicá-las.
} 
materiais didático-pedagógicos da disciplina, foco desta pesquisa, tais como, planos de ensino, links para as videoaulas, sites com temas ou notícias relacionadas aos conceitos trabalhados e as atividades avaliadas, as quais consistem de situações-problemas. Estas atividades avaliadas eram resolvidas em grupo, tanto no espaço da sala de aula quanto fora deste e tinham por objetivo promover a interação entre os estudantes e o meio (ambiente virtual), um dos pressupostos da Teoria da Biologia do Conhecer.

\subsection{Material concreto}

Possibilita, por meio da experimentação, o desenvolvimento do raciocínio, da reflexão, dos questionamentos e das estratégias para construção do conhecimento, o que conduz o estudante a aprender no seu próprio tempo (LORENZATO, 2006). Com base nisto, acreditamos que a manipulação e exploração do material concreto possam contribuir para o processo de ensino e de aprendizagem da Estatística e da Probabilidade, desde que utilizados de forma a explorar o seu potencial pedagógico. Fernandes et al (2009) sugerem que, primeiramente, seja feita simulação com materiais concretos e, na sequência, que os estudantes estabeleçam comparações com simulações em computador, a fim de aumentar a compreensão sobre o experimento.

\subsection{Simulação}

Outra importante contribuição das tecnologias digitais no ambiente educacional diz respeito à possibilidade de trabalhar com a simulação eletrônica a partir de softwares específicos e sites na internet, conforme pode-se observar na Figura 3, que apresenta um simulador para o Problema de Monty Hall. Chance, delMas e Garfield (2004) argumentam que os alunos se interessam mais na aprendizagem da Probabilidade e da Estatística quando são usadas simulações.

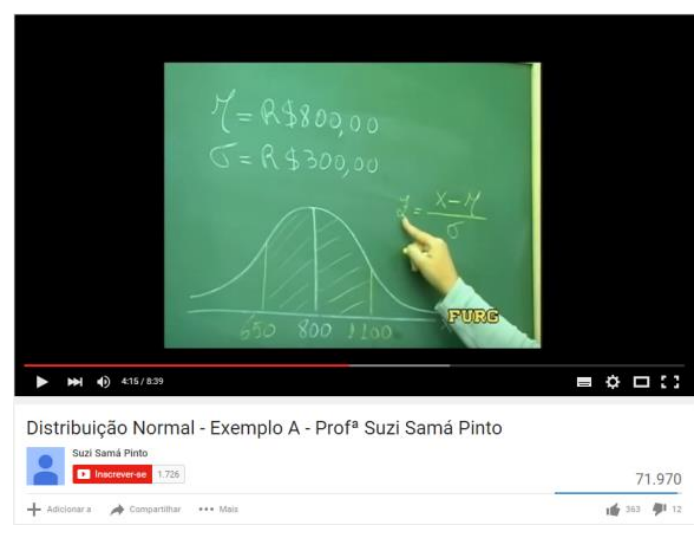

Figura 2. Videoaula

Fonte: https://goo.gl/XU16JA 


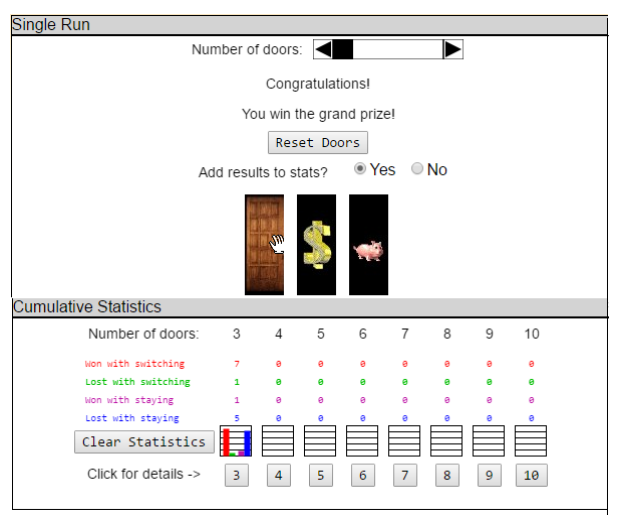

Figura 3. Simulador

Fonte: http://goo.gl/aI4BXB

Desta forma, o uso de software que permitem simular virtualmente, por exemplo, o comportamento aleatório de um determinado fenômeno presente no cotidiano dos estudantes, pode auxiliar no desenvolvimento cognitivo destes. Para Fernandes et al (2009), o uso de programas de simulação possibilita melhorar a intuição probabilística, uma vez que torna possível a exploração e a descoberta de conceitos e princípios que de outro modo seriam muito mais abstratos.

De acordo com Heckler, Saraiva e Oliveira Filho (2007), o uso da tecnologia digital tanto pode contribuir para o processo de aprendizagem dos estudantes quanto atrapalhar em certos momentos, já que pode desestimular a leitura de textos, levando os alunos a se restringirem à observação de imagens e simulações. Os autores ressaltam que cabe ao professor dosar o tempo de uso de cada recurso, seja vídeo, simulação, material concreto, entre outros, de forma a criar um "ambiente em que o aluno possa perguntar, refletir, debater, pesquisar, onde ambos [alunos e professores] possam se sentir responsáveis" (p. 273) pelo processo de ensino e aprendizagem.

Nessa seção apresentamos algumas das atividades propostas na SalAEst. A fim de investigar a contribuição dessas, no final de uma das disciplinas ministradas nesse ambiente educacional, foi disponibilizado aos estudantes de graduação um instrumento de avaliação. Na próxima seção apresentamos o instrumento de avaliação e a metodologia de análise.

\section{Metodologia}

No final do $1^{0}$ semestre de 2016, foi disponibilizado, aos estudantes da disciplina de Estatística, um instrumento de avaliação com questões abertas e fechadas. Este teve por finalidade avaliar a sala de aula de Estatística planejada de acordo com a modalidade Blended Learning. Os sujeitos da pesquisa foram estudantes de graduação do curso de Administração que tiveram as aulas de Estatística ministradas na SalAEst.

Nas questões fechadas, os estudantes atribuíram uma nota de 0 (zero) -correspondendo a "discordo totalmente" - a 10 (dez) - "concordo totalmente" - a cada uma das assertivas do instrumento. Na análise destas questões, utilizamos a Estatística Descritiva. As questões abertas foram analisadas por meio do Discurso do Sujeito Coletivo (DSC), proposto por Lefèvre e Lefèvre (2000).

Tal metodologia consiste na construção de discursos oriundos da junção de fragmentos das partes mais importantes das manifestações individuais dos sujeitos da pesquisa, denominadas aqui de Expressões-Chave. A seguir, identifica-se a Ideia Central de cada Expressão-Chave, a qual, segundo Lefèvre e Lefèvre (2000), revela a essência do sentido do discurso individual de cada participante da pesquisa. 
O passo seguinte do processo de análise se configura no agrupamento das Ideias Centrais semelhantes. Por fim, as Ideias Centrais semelhantes são reduzidas a apenas uma e as Expressões-Chave correspondentes são organizadas de forma a constituir um discurso coletivo, que reúne as diferentes manifestações dos sujeitos. Quando o conteúdo das Expressões-Chave é basicamente o mesmo, o pesquisador pode escolher o que melhor transmita a Ideia Central explicitada. O discurso, elaborado com trechos das Expressões-Chave dos diferentes participantes da pesquisa, permite uma melhor percepção sobre as relações existentes entre o conteúdo empírico de suas manifestações e os referenciais teóricos que embasam a pesquisa.

\section{Avaliação da SalAEst pelos estudantes da graduação}

Dos 38 estudantes que iniciaram a disciplina, 29 participaram até o final do semestre, sendo que destes, 26 responderam o instrumento de avaliação. Pode-se constatar um número expressivo de evasão, a qual pode ser justificada em decorrência do curso ser ofertado no turno da noite, o que dificulta conciliar os estudos com o trabalho.

A idade média dos estudantes que participaram da avaliação é de 28,3 anos e o desvio-padrão é de 8,08, 50\% dos estudantes têm idade inferior a 25 anos, 54\% são do sexo feminino e $77 \%$ trabalham.

Na Tabela 1 apresentamos as questões fechadas que constaram no instrumento as quais os estudantes atribuíram uma nota de acordo com a concordância a cada uma delas.

Tabela 1 - Questões do instrumento de avaliação da disciplina

\begin{tabular}{|c|c|c|c|c|}
\hline & Questões & Média & Min.* & D.P.* \\
\hline 1 & $\begin{array}{l}\text { A rodada de exercícios contribuiu na aprendizagem dos conceitos } \\
\text { estatísticos trabalhados na disciplina. }\end{array}$ & 8,4 & 3 & 1,97 \\
\hline 2 & $\begin{array}{l}\text { O trabalho em grupo contribuiu para a aprendizagem dos conceitos } \\
\text { de estatística. }\end{array}$ & 8,6 & 2 & 2,02 \\
\hline 3 & $\begin{array}{l}\text { As atividades avaliadas foram coerentes com os conteúdos } \\
\text { abordados em sala de aula. }\end{array}$ & 9,6 & 7 & 0,81 \\
\hline 4 & $\begin{array}{l}\text { As videoaulas contribuíram para a compreensão dos conceitos } \\
\text { estatísticos da disciplina. }\end{array}$ & 9,3 & 6 & 1,26 \\
\hline 5 & Aprendo mais quando estudo sozinho. & 5,9 & 0 & 3,64 \\
\hline 6 & $\begin{array}{l}\text { A organização da disciplina no Moodle contribuiu no planejamento e } \\
\text { desenvolvimento de meus estudos. }\end{array}$ & 9,1 & 3 & 1,56 \\
\hline 7 & $\begin{array}{l}\text { As atividades avaliadas auxiliaram na compreensão dos conceitos } \\
\text { estatísticos trabalhados na disciplina. }\end{array}$ & 8,7 & 5 & 1,57 \\
\hline 8 & $\begin{array}{l}\text { A professora promoveu o interesse dos alunos pela disciplina, } \\
\text { incentivando-os à investigação teórica e/ou prática, ao } \\
\text { questionamento e à realização de leituras complementares. }\end{array}$ & 9,0 & 5 & 1,47 \\
\hline 9 & $\begin{array}{l}\text { O método de ensino e o material disponibilizado foram adequados à } \\
\text { proposta da disciplina. }\end{array}$ & 9,3 & 6 & 1,20 \\
\hline 10 & $\begin{array}{l}\text { A organização da sala em mesas hexagonais possibilitou maior } \\
\text { integração entre os colegas da turma. }\end{array}$ & 8,7 & 5 & 1,57 \\
\hline
\end{tabular}

* Min. = mínimo; D.P. = desvio-padrão

Fonte: Autor

A questão 5 "Aprendo mais quando estudo sozinho" apresentou a menor média $(5,9)$ e maior dispersão (D.P.= 3,64). A questão 2 apresentou média 8,6, o que evidencia a contribuição do trabalho em grupo na compreensão dos conceitos estatísticos. Garfield (1993) defende que o professor realize atividades de aprendizagem em grupo, a fim de promover a construção do 
conhecimento estatístico pelos estudantes. Neste cenário, o papel do professor muda de transmissor da informação para o de orientador do processo de aprendizagem.

A maior nota mínima $(7,0)$ e maior média $(9,6)$ foi atribuída à questão 3 . Como esta também apresentou a menor dispersão $(0,81)$, verificamos consenso entre os estudantes em relação à coerência entre as atividades avaliadas e o conteúdo abordado na disciplina.

Em relação à contribuição das videoaulas para a compreensão dos conceitos estatísticos da disciplina (questão 4), também se obteve média e nota mínima altas ( 9,3 e 6,0 , respectivamente). Este resultado evidencia que os alunos aprendem melhor por meio de recursos didáticos que explorem os estímulos visuais e sonoros, conforme defendido por Mattar (2009). Nesta mesma esteira, Marcova (2000) defende que os recursos didáticos que integram som, texto e imagens intensificam as emoções e ativam a atividade cerebral, produzindo vários neurotransmissores e estimulando novas sinapses.

A questão 9 "O método de ensino e o material disponibilizado foram adequados à proposta da disciplina" obteve a mesma média e nota mínima da questão 4. Além disso, estas duas questões apresentam baixa dispersão (1,20 e 1,26 respectivamente), o que demonstra consenso entre os estudantes.

Finalizada a análise quantitativa passamos a analisar as questões abertas por meio do DSC. Nessas os estudantes puderam avaliar os aspectos que consideraram positivos ao longo da disciplina (Quadro 1); as dificuldades encontradas (Quadro 2) e o que poderia ser modificado na disciplina a fim de contribuir mais na compreensão dos conceitos. Essa última questão foi incorporada as outras duas ao longo do processo de análise.

Quadro 1. Discurso do Sujeito Coletivo dos aspectos positivos da disciplina

O bom humor e compreensão da professora sempre presente e disposta a tirar as dúvidas a qualquer momento. Sua didática e atenção são incomparáveis e atraem o interesse sobre a disciplina e faz a disciplina ser mais bacana. A organização da sala em mesas hexagonais facilita a interação com os colegas para a realização das atividades devido aos trabalhos em grupo, os quais contribuíram para tirar as dúvidas. A organização da disciplina no moodle, as videoaulas, o livro que possui o conteúdo explicado de forma bem didática e os exercícios avaliados com uma data pré-agendada. Inovação na busca de métodos de ensino melhores que os tradicionais. Única disciplina que dispõem de vários jeitos para fazer o aluno aprender, demonstrando a vontade de ensinar e não apenas apresentar o que está pré-escrito.

Na proposta pedagógica da SalAEst, busca-se disponibilizar diferentes recursos didáticos respeitando os diferentes estilos de aprendizagem. Neste ambiente educacional o papel do professor é criar um espaço de experimentação e diálogo. O diálogo periódico e recorrente entre a professora e os estudantes contribui para que esta compreenda o raciocínio dos alunos e as dificuldades por esses enfrentadas. Além disso, Garfield (2013), salienta que a troca de experiências entre os estudantes, promovem o confronto de ideias e a socialização das soluções encontradas. Segundo Bittencourt et al. (2004), a produção do conhecimento não se dá de forma solitária, mas sim de forma coletiva. Maturana (1993) também destaca a importância do trabalho coletivo, pois este considera a Educação como um processo de transformação na convivência, em que professores e estudantes irão modificar-se enquanto permanecerem em interações recorrentes.

Quadro 2. Discurso do Sujeito Coletivo das dificuldades encontradas na disciplina

Não tive dificuldade com a matéria, mas sim com a falta de tempo para estudo em casa e para fazer os exercícios. Muito conteúdo em pouco tempo, junto com as outras disciplinas acaba nos faltando tempo para estudar mais. A disciplina foi apresentada de forma coerente e de pouca dificuldade. Apenas nos cálculos e interpretação exige atenção e muito estudo, assim como reconhecer quais tabelas usar para cada exercício. No trabalho em grupo faltou mais interesse dos integrantes. Tive dificuldade de concentração durante as aulas, por estar sempre reunido em grupo. 
A falta de tempo para os estudos foi uma das dificuldades apontadas pelos estudantes. Essa pode ser explicada em decorrência do curso ser noturno e a maioria dos estudantes trabalharem. Vale aqui destacar que a disciplina foi planejada de forma a aproveitar ao máximo o tempo dos estudantes em sala de aula e em potencializar a interação e a troca de experiências entre os mesmos. No entanto, parece que alguns estudantes tiveram dificuldade de adaptação a um ambiente mais flexível que exigia maior autonomia e independência.

\section{Considerações}

O planejamento da SalAEst, bem como as pesquisas e atividades da equipe do LabEst buscam a construção de um ambiente flexível de aprendizagem da Estatística, envolvendo a utilização de vídeos, jogos, simulações, coleta de dados, atividades em grupo e individualizadas. Neste ambiente de convivência e de transformação individual e coletiva, buscamos conciliar a organização do processo de ensinar e aprender com a possibilidade de adaptá-lo a cada aluno e ao grupo, em que o tempo de cada um é respeitado.

Os resultados apresentados, tanto na análise quantitativa quanto qualitativa, apontam que os estudantes valorizaram a diversidade de suportes e estratégias pedagógicas utilizados ao longo da disciplina na SalAEst. Outro aspecto valorizado nesta pesquisa diz respeito a organização da sala em mesas hexagonais, a qual facilitou a interação entre os colegas na realização das atividades em grupo. Por outro lado, foi possível verificar que esta organização dificultou a concentração de alguns alunos, talvez por não estarem acostumados a um ambiente educacional flexível e descontraído. Os estudantes ressaltaram o fato desta ser a única disciplina do curso que contempla diferentes formas de aprendizagem.

Enfatizamos a importância da criação de um ambiente educacional motivador, que possibilite a integração, cooperação e a investigação nos momentos presenciais e a distância. Este ambiente, com o suporte das tecnologias digitais, revela-se como um promotor da autonomia do estudante e da discussão e reflexão dos conceitos de Estatística.

\section{Agradecimentos}

Agradecemos ao Conselho Nacional de Desenvolvimento Científico e Tecnológico - CNPq pelo apoio financeiro.

\section{References}

Bacich, L., Moran, J. M. Aprender e Ensinar com foco na Educação Híbrida. Revista Pátio. n. 25, 2015.

Belloni, M. L. Educação a Distância. 4 ed. Campinas: Autores Associados, 2006.

Bittencourt, C. S., Grassi, D., Arusievicz, F., Tonidandel, I. Aprendizagem Colaborativa Apoiada por Computador. Revista Novas Tecnologias na Educação. v. 2, n. 1, março, 2004.

Chance, B., delMas, R. C., \& Garfield, J. Reasoning about sampling distributions. In D. Ben-Zvi \& J. Garfi eld (Orgs.), The challenge of developing statistical literacy, reasoning and thinking. Amsterdam: Kluwer, 2004, p. 295-323.

Fagundes, L., Sato L. S. e Laurino, D. L. Aprendizes do futuro: as inovações começaram. Coleção Informática para a Mudança na Educação, 2012. MEC.http://www.dominiopublico.gov.br/download/texto/me003153.pdf, maio.

Florêncio, P. H. B., Santos Neto, A. S., Dantas, M. J. P. Análise do problema de Monty Hall: um enfoque bayesiano. Simpósio Acadêmico de Engenharia de Produção. Universidade Federal de Viçosa, 2014. http://www.saepro.ufv.br/wp-content/uploads/2014.13.pdf, março.

Gal, I. Adult's Statistical literacy: Meanings, Components, Responsabilities. International Statistical Review, n. 70, 2002.

Garfield, J. B., Gal, I. Teaching and Assessing Statistical Reasoning. In: STIFFL, CURCIO, F. Developing Mathematical Reasoning in Grades K-12. USA: The National Council of Teachers of Mathematics,1999. 
Heckler, V., Saraiva, M. F.O., Oliveira Filho, K. S. Uso de simuladores, imagens e animações como ferramentas auxiliares no ensino/aprendizagem de óptica. Revista Brasileira de Ensino de Física. v. 29, n. 02, 2007, p. 267-273.

Lefèvre, F., Lefèvre, A. M. C. Discurso do Sujeito Coletivo: um novo enfoque em pesquisa qualitativa. 2 ed. Caxias do Sul: Educs, 2005.

Markova, D. O natural é ser inteligente. São Paulo: Summus, 2000.

Marsh, G. E. II, Mcfadden, A. C. Y Price, B. Blended Instruction: Adapting Conventional Instruction for Large Classes. Journal of Distance Learning Administration, 4, n. 4, Winter 2003.

Mattar, J. Youtube na educação: o uso de vídeos em EaD, 2009. Disponível em: http://www.pucrs.br/famat/viali/recursos/vlogs/YouTube.pdf. Acesso em: março/2015.

Maturana, H. R.; Verden-Zöller. G. Amar e Brincar: fundamentos esquecidos do humano do patriarcado à democracia. 2 ed. São Paulo: Palas Athena, 2009.

Maturana, H. R., Varela, F. A árvore do conhecimento: as bases biológicas da compreensão humana. 5 ed. São Paulo: Palas Athena, 2005.

Mendonça, O. L.; Lopes, C. E. Modelagem Matemática: um ambiente de aprendizagem para a implementação da Educação Estatística no Ensino Médio. Boletim de Educação Matemática, v. 24, n. 40, dezembro, 2011, p. 701-724.

Moraes, M. C. O Paradigma Educacional Emergente. 13 ed. Campinas, SP: Papirus, 2007.

Moran, J. M. (2013) Novos modelos de sala de aula. Disponível em: http://www2.eca.usp.br/moran/wpcontent/uploads/2013/12/modelos_aula.pdf, Acesso em: jun/2015.

Oliveira, S. Geração Y: o nascimento de uma nova versão de líderes. São Paulo: Integrara Editora, 2010.

Pascual, M. P. El Blended learning reduce el ahorro de la formación on-line pero gana en calidad. Educaweb, n. 69. Disponível em: <http://www.educaweb.

com/esp/servicios/monografico/formacionvirtual/1181108.asp. Acesso em: julho, 2003.

Pellanda, N. M. C. Maturana \& a Educação. Belo Horizonte: Autêntica, 2009.

Porciúncula, M. M. S, Samá, S. P. Teaching Statistics Through Learning Projects. Statistics Education Research Journal, vol. 13, no 2, p. 177-186, 2014.

Samá, S. P.; Araújo, M. S.; Laurino, D. P. A Educação a partir da Biologia do Conhecer na Sociedade da Informação e Comunicação. I Seminário Internacional de Educação em Ciências, Rio Grande. I Sintec, v. II, 2011, p. 813-823.

Twigg, C.A. Improving Learning and Reducing Costs: Lessons Learned from Round I of the Pew Grant Program in Course Redesign, 2003. Disponível em: <http://www.center.rpi.edu/PewGrant/Rd1intro.html>, Acesso em: julho, 2003.

Submetido para avaliação em 15 de janeiro de 2017

Aprovado para publicação em 22 de março de 2017

\section{Gabriela Machado Moura}

Instituto de Matemática, Estatística e Física - Universidade Federal do Rio Grande - FURG, Brasil, gabriela_mmoura@hotmail.com

Suzi Samá

Instituto de Matemática, Estatística e Física - Universidade Federal do Rio Grande - FURG, Brasil, suzisama@furg.br 